\title{
2021 - BRIGHTER LIGHT AT THE END OF THE TUNNEL
}

DOI: https://dx.doi.org/10.21857/94kl4cz41m

\section{Marko Pećina, Vida Demarin}

The last two editorials to our journal were mainly dedicated to the situation caused by the COVID-19 pandemic in our country, our city and the Croatian Academy of Sciences and Arts. Let us briefly remind our readers of the titles of these two texts: Pandemic and 2020 Zagreb Earthquake Didn't Stop Us (RAD 50-51, 2020); 2020 - Annus Horribilis (RAD 52-53, 2020). The title of our today's Editorial shows how very optimistic and hopeful we are that the following issues will cease to tackle the difficulties related to the COVID-19 pandemic, and that only articles on the experience gained in suppressing this plague will be published. The title of our current Editorial has been chosen based on the information regarding the successful combatting of the third wave of the pandemic in Croatia, joined with the increasingly positive response of our citizens to the COVID-19 vaccination. By the end of June, when this issue of RAD is published, over $50 \%$ of adult population in Croatia will hopefully be vaccinated; it is furthermore planned for more than 70 $\%$ of the overall population to be vaccinated in the near future. We are thus full of optimism and belief in the return of what we usually refer to as normal life.

It is evident from the contents of the present issue of our journal that despite all the obstacles caused by the pandemic, our authors have managed to remain active in the publicist sphere. The diverse contents include the following: a paper by our Bulgarian colleagues, entitled Bulgarian Mutations Spectrum Cadasil : Our Experience (1); an article on epilepsy in multiple sclerosis patients (2); a paper tackling a more accurate estimation of kidney function in elderly citizens (3); an article dealing with the prevalence of non-motor symptoms in patients suffering from Parkinson's disease(4); a paper on the endovascular treatment of subclavian stenosis(5); an article on meralgia paresthetica(6); an article on robotics in urology(7); and a paper from the domain of the history of medicine(8). Hence, we hope that every reader will be able to find something of interest and novelty for themselves.

We take great pride in our NEWS \&EDUCATION section, as it is this part of our journal, presenting diverse events taking place at our Department, that justifies the title of the present Editorial. At our Academy and our Department, we are slowly yet safely approaching the so-called NORMAL sphere, and leaving behind the online and hybrid events. We are convinced that by September we will manage to restrain the COVID-19 pandemic, and succeed in exiting the tunnel and stepping into the daylight. We promise that the title of the editorial to our December 2021 issue will no longer include the COVID-19 pandemic.

Dear readers, we owe you a brief explanation regarding the change of scope of our column entitled ESSAY INTERVIEWS. In the issue $544=52-53$ of our periodical RAD CASA - Medical Sciences, we introduced a new column entitled Essay Interviews with Corresponding Members of the Croatian Academy of Sciences and Arts, Department of Medical Sciences. For the present issue 54-55, we decided to expand the scope thereof and include interviews with other internationally renowned alumni of the Faculty of Medicine, University of $\mathrm{Za}$ greb, so that we could profile even those alumni who are not Corresponding Members of the Croatian Acad- 


\section{EDITORIAL}

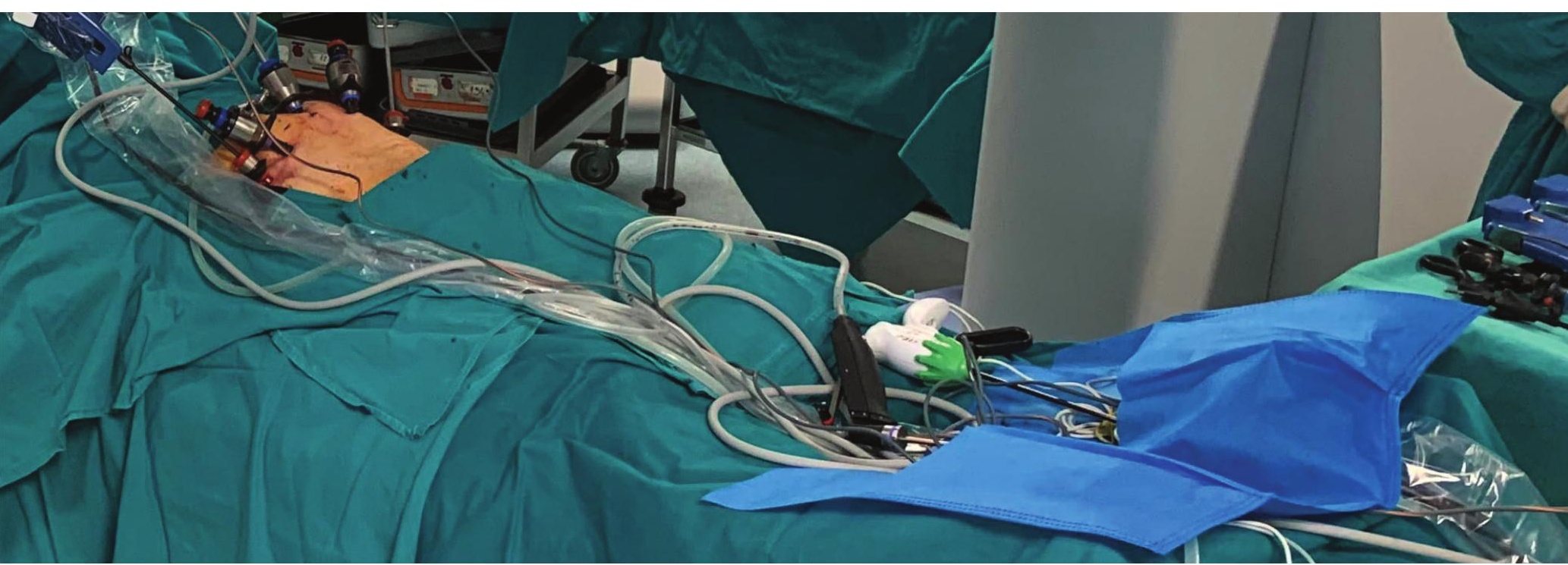

Figure 1. Robotic setting in the operating theatre. There are three robotic hands controlled by the operator. One is holding the camera and the other two are holding instruments. Additional trocars are used for laparoscopic instruments controlled by assistant surgeons. (ref.7)

emy of Sciences and Arts. This change further required from us a change in the title of this series of interviews. We thus gave it a Latin title: Illustrissimi Alumni Facultatis Medicae Zagrabiensis. Dr. Ivan Damjanov, Emeritus Professor of Pathology at the University of Kansas School of Medicine, Kansas City, USA, who is also a Corresponding Member of the Croatian Academy of Sciences and Arts, has agreed to continue conducting these interviews. On this occasion, we repeatedly cordially thank him for his efforts.

We wish all our authors and readers a pleasant summer holiday, and a happy reunion afterwards in our places of work and within our families. In this context, the famous quote by William of Orange comes to mind: "It is not necessary to hope in order to act, nor to succeed in order to persevere."

\section{REFERENCES:}

1. Tourtourikov I, Kadiyska T, Mitev V, Todorova A, Titianova E. Bulgarian mutation spectrum in cadasil: Our experience RAD CASA - Medical Sciences. 547=54-55 (2021): 10-18 DOI: https://dx.doi.org/10.21857/ yrvgqtezr9

2. Zavoreo I, Jurašić M J, Zadro Matovina L, Bašić Kes V. Incidence of epilepsy in multiple sclerosis patients: RAD CASA - Medical Sciences. 547=54-55 (2021): 20-23 DOI: https:// dx.doi.org/10.21857/ m16wjcexo9

3. Matašin M, Domislović V, Fuček M, Gellineo L, Jelaković A, Dika Ž, Jelaković B. Berlin Initiative Study 1 equation and HUGE formula for more accurate estimation of kidney function in elderly RAD CASA - Medical Sciences. 547=5455 (2021): 24-31 DOI: https://dx.doi.org/10.21857/ ydkx2cw8k9

4. Lasić S, Bašić S, Sporiš D, Džamonja G. Prevalence of nonmotor symptoms in patients with Parkinson's disease in Split-Dalmatia County RAD CASA - Medical Sciences. 547=54-55 (2021): 38-48 DOI: https://dx.doi. org/10.21857/90836c760y
5. Dobrota S, Filipović - Grčić L, Perkov D, Đermanović Dobrota V, Lukinović - Škudar V, Vrkić Kirhmajer M, Butković Soldo S, Coce N. Endovascular treat- ment of subclavian stenosis - single center experience RAD CASA Medical Sciences. 547=54-55 (2021): 32-37 DOI: https:// dx.doi.org/10.21857/ m8vqrtqv89

6. Madiraca Glasović D, Šlaus N, Šitum M, Pećina M. Meralgia paresthetica - lateral femoral cutaneous nerve entrapment RAD CASA - Medical Sciences. 547=54-55 (2021): 56-63 DOI: https://dx.doi.org/10.21857/ mzvkptq6v9

7. Hudolin T, Kuliš T, Knežević N, Penezić L, Zekulić T, Hauptman D, Sajić H, Kaštelan Z. Robotics in urology: A short review and a single-centre experience with SenhanceTM robotics system RAD CASA - Medical Sciences. 547=54-55 (2021): 64-68 DOI: https://dx.doi.org/10.21857/ y26kec46d9

8. Blažević Z. How to Create a Medical Knowledge: the Case of Georgius Baglivi (1668-1707) RAD CASA - Medical Sciences. 547=54-55 (2021): 50-55 DOI: https://dx.doi. org/10.21857/9e31lhv8pm 